\title{
Sliding Mode Control of BLDCM Based on a Disturbance Observer
}

\author{
Shunxiang Hou, Yupei Zhang \\ Nanchang Institute of Science \& Technology, Nanchang, 330108, China
}

\begin{abstract}
Keywords: Brushless DC Motor; Sliding mode control; Disturbance Observer; Chattering
\end{abstract}
\begin{abstract}
The aim of this paper is to design a sliding-mode variable structure controller (SMC) which based on the model of BLDCM. SMC is insensitive to turbulence which can depress influence of disturbances to BLDCM, and a novel variable exponent reaching law which can reduce the shuttering effectively is designed. A disturbance observer which is used to eliminate the error of the system, and it has a better effect. The simulation illustrates that the controller (SMC) express better in the control of the BLDCM and it has a good strong robust against disturbances.
\end{abstract}

\section{Introduction}

The brushless DC motor has good speed control characteristic and higher operating efficiency as DC motor, and all so has high reliability as AC motor.. Because of its simple structure and convenient maintenance, BLDCM has a wide application in the industrial field ${ }^{[1-3] \text {. }}$

The brushless DC motor usually use PID controller, but PID controller can't meet the requirement of servo system because of its poor regulation of parameter change and disturbance change. The neural network and model reference adaptive control algorithm is difficult to realize because of its complex structure, large computation and high hardware requirements ${ }^{\text {[4-5] }}$. In fuzzy control, the fuzzy rules have mutual influence, and it has a high requirements for operator experience, so the effect is not ideal ${ }^{[6-9]}$.

Sliding mode variable structure control ${ }^{[10]}$ is insensitive to parameter perturbation and internal and external disturbances, and is widely used in Brushless DC motor control. Sliding mode variable structure control achieves its strong anti-interference ability through its discontinuous switching phase, which undoubtedly improves the robustness of the system, but it also brings buffeting to the system, so that it has limit in the engineering application. In document ${ }^{[11]}$, an exponential approach law is used to reduce the chattering of the system. This method has achieved good results, but the exponential approach law only makes the system approach a region of the origin, and it can not really make the system approach the origin.

Document ${ }^{[12-16]}$ uses intelligent control combined with variable structure control to suppress chattering, but there is no compensation for the change of load torque. In this paper, a sliding mode variable structure speed controller is proposed. The torque observer is used to compensate the system torque, so that the DC motor has a high speed regulation performance.

\section{The mathematical model of brushless DC motor}

Brushless DC motor adopts star connection method, and no center line is connected. When it works normally, the two phases are connected, so it works in 6 states, and the counter electromotive force is trapezoidal wave,and its flat top width is $2 / 3$ angle. The motor works in the state that the magnetic circuit is unsaturated. So the voltage balance equation of three-phase winding is:

$$
\left[\begin{array}{l}
u_{a} \\
u_{b} \\
u_{c}
\end{array}\right]=\left[\begin{array}{lll}
r & 0 & 0 \\
0 & r & 0 \\
0 & 0 & r
\end{array}\right]\left[\begin{array}{l}
i_{a} \\
i_{b} \\
i_{c}
\end{array}\right]+\mathrm{D}\left[\begin{array}{ccc}
L & M & M \\
M & L & M \\
M & M & L
\end{array}\right]\left[\begin{array}{l}
i_{a} \\
i_{b} \\
i_{c}
\end{array}\right]+\left[\begin{array}{c}
e_{a} \\
e_{b} \\
e_{c}
\end{array}\right]
$$

Where $r$ is resistance of stator phase winding, $u_{a}, u_{b}, u_{c}$ is the voltage of Stator phase winding, $e_{a}, e_{b}, e_{c}$ is the counter electromotive force of Stator phase winding, $i_{a}, i_{b}, i_{c}$ is the current of Stator 
phase winding, $L$ is the self-induction of phase winding, $M$ is the mutual inductance between two phase windings, $\mathrm{D}$ is the differential operator $\mathrm{D}=\mathrm{d} / \mathrm{d} t$.

According to the motor voltage balance equation and the torque balance equation. We obtain the state equation of Brushless DC motor power system as

$$
\left\{\begin{array}{l}
\dot{x}_{1}=X_{2} \\
\dot{x}_{2}=-\frac{\left(B r^{\prime}+K_{t} K_{e}\right)}{L^{\prime} J} X_{1}-\frac{\left(r^{\prime} J+B L^{\prime}\right)}{L^{\prime} J} X_{2}+\frac{K_{t}}{L^{\prime} J} u-\frac{r^{\prime}}{L^{\prime} J} T_{l}
\end{array}\right.
$$

In the control of Brushless DC motor, the controller achieves the purpose of controlling the speed of the motor by controlling the output average voltage of the PWM inverter.

The design of sliding Mode Controller based on a disturbance observer

\subsection{Sliding mode control based on reaching law}

Consider the following nonlinear affine systems

$$
\dot{x}=f(x)+b(x) u+d(t)
$$

Where $x \in \mathbf{R}^{n}, u \in \mathbf{R}^{m}$ are system status and control vector, $f, b, d(t)$ are smooth uncertain vector field, $d(t)$ is system disturbance.

Setting the sliding mode switching surface expression as

$$
s=c x
$$

Where $C$ is a $\mathrm{N}$-dimensional row vector.

Setting the control input of affine system as

$$
u_{i}(x)= \begin{cases}u_{i}^{+}(x) & s_{i}(x)>0 \\ u_{i}^{-}(x) & s_{i}(x)>0\end{cases}
$$

In the phase plane, when the state is not in the sliding surface, the variable structure controller will force the state to the trend of the sliding surface. When the state is running to the sliding surface, the system state will always be on the sliding surface movement to state stable point.

In order to reduce the chattering, the following exponential reaching law is proposed

$$
\dot{s}=-k s-\alpha|s| \operatorname{sgn}(s)
$$

When approaching the sliding surface, the exponential term decreases rapidly and approaches zero. $^{-\alpha|s| \operatorname{sgn}(s)}$ the phase change plays a major role. The $|s|$ term makes the control term $-\alpha|s| \operatorname{sgn}(s)$ in the variable structure control law smaller, and approaches the origin finally.

A controller based on the approach law is designed

$$
\dot{s}=c \dot{x}=\text { slaw }
$$

Where slaw is the approach law (6).

Substituting the expression (2) into (7), we obtain the control input

$$
u=-[c b(x)]^{-1}[c f(x)+c d(t)+\text { slaw }]
$$

\subsection{The design of sliding Mode Controller}

For motor models (2), setting the system command speed as $\omega^{*}$, and we have system tracking error as

$$
e=\omega^{*}=\omega
$$


Substituting the expression (9) into (2), we obtain

$$
\left\{\begin{array}{l}
\dot{x}_{1}=X_{2} \\
\dot{X}_{2}=-\frac{\left(B r^{\prime}+K_{t} K_{e}\right)}{L^{\prime} J} X_{1}-\frac{\left(r^{\prime} J+B L^{\prime}\right)}{L^{\prime} J} X_{2}+\frac{\left(B r^{\prime}+K_{t} K_{e}\right)}{L^{\prime} J} \omega^{*}-\frac{K_{t}}{L^{\prime} J} u+\frac{r^{\prime}}{L^{\prime} J} T_{1}
\end{array}\right.
$$

Where $x_{1}=e ; x_{2}=\dot{e}$.

So

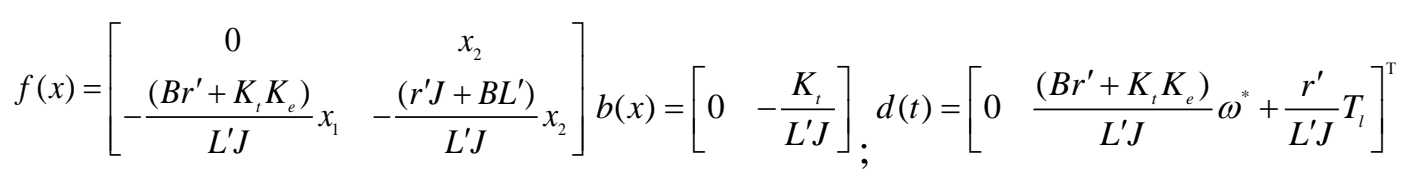

Setting ${ }^{c}=\left[\begin{array}{ll}c_{1} & 1\end{array}\right]^{\mathrm{T}}$

Substituting the above expression into (8), we obtain the control input ${ }^{u}$.

In order to reduce the steady-state error of the system, it is necessary to observe the disturbance, and then use the observation value to feed forward the disturbance and eliminate the steady-state error of the system.

In this paper the disturbance torque observer is constructed by using the torque, current and speed of the system.

Torque equation of Brushless DC motor can be written as

$$
K_{t} i-T_{l}=J \frac{\mathrm{d} \omega}{\mathrm{d} t}+B \omega
$$

Design observer that

$$
\hat{T}_{l}=\frac{K_{t} i-J \frac{\mathrm{d} \omega}{\mathrm{d} t}-B \omega}{m s+1}
$$

Where $m$ is the constant. In order to reduce the high frequency noise caused by the differential speed in the numerator, the filter is added to the observer. The error of the observer decays exponentially to zero with time, and the closure speed is determined by $1 / \mathrm{m}$.

\section{Numerical Simulations}

In the actual simulation, the selected prototype parameters are as follows: Phase resistance of stator $R=2.3 \Omega$, Phase inductance $L=6.8 \mathrm{mH}, J=3 \times 10^{-3} \mathrm{Kg} \cdot \mathrm{m}^{2}, K_{t}=0.93, \mathrm{Ke}=0.95, f=0.001 \mathrm{~N} \cdot \mathrm{s}$, $B=0.0001$.

Verify the controller through the MATLAB/SIMULINK. $K_{1}=0.007420, K_{2}=0.95023, K_{3}=0.4$, $K_{4}=0.95023, K_{5}=2.473, K_{6}=10, c_{1}=500,1 / m=0.019$.

In order to observe the performance of the variable structure controller based on the disturbance observer, the performance of the proposed controller is compared with that of the ordinary PID controller. Fig. 2 is the speed response curve of the two controller when the load has a sudden change. At $0.1 \mathrm{~s}$, the load torque jumps from $20 \mathrm{~N} \cdot \mathrm{S}$ to $100 \mathrm{~N} \cdot \mathrm{S}$. The response curve of the variable structure controller is faster than that of the ordinary PID controller, and the fluctuation is small. It shows that the controller designed in this paper has fast response speed, better suppression of overshoot, better control effect on load change. Fig. 3 is the speed response curve of the controller when the phase resistance varies from $2.3 \Omega$ to $4.5 \Omega$, and it indicates that the controller is robust to parameter variations. 


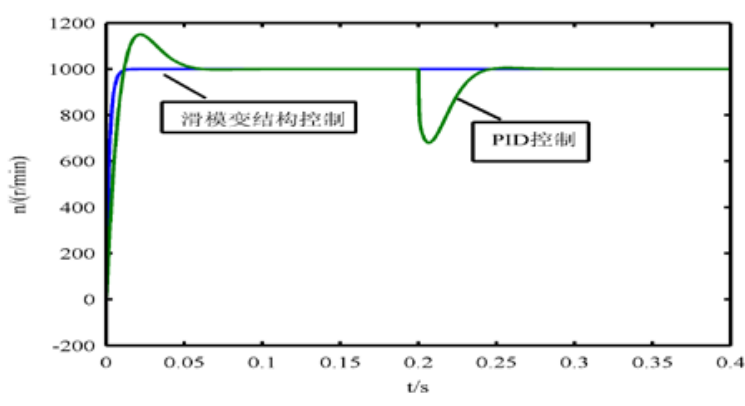

Fig 1 The speed response curve

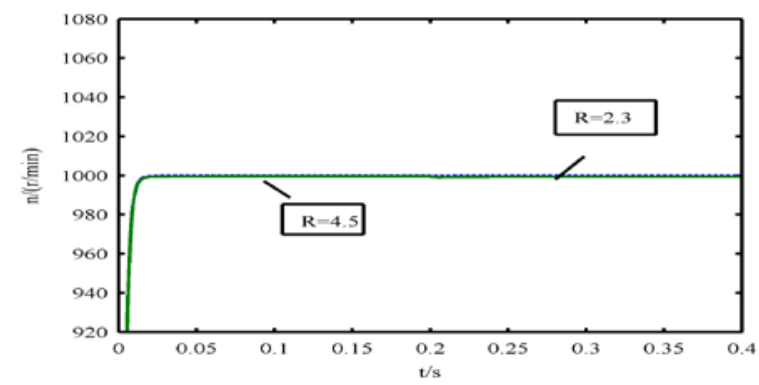

Fig 2 The speed response curve under different resistances

\section{Conclusion}

A variable structure controller of Brushless DC motor based on disturbance observer is designed in this paper. The controller has very good speed response and robustness. The disturbance observer can observe the disturbance of the system, compensate the disturbance of the system, and it obtains better control results. Simulation results verify the good performance of the controller.

\section{Acknowledgements}

This work is supported by Science and technology research project of Jiangxi Provincial Education Department (GJJ161221)

\section{References}

[1] ZHANG C. The principle and application of DC brushless motor [M]. Beijing: The Publishing House of Mechanical Industry. 1996.

[2] XIA C L, LIU J H, YU W, et al. Variable Structure Control of BLDCM Based on Extended State Observer[J]. Proceedings of the CSEE, 2006, 26(20): 139-143.

[3] WANG Z S, ZHANG Z L, CHEN H M. Reduction of Commutation Torque Ripple in Brushless DC Motors [J]. Control Engineering of China, 2010, 17(3): 332-350.

[4] Rubaai A, Kotaru R, Kankam M D.A continually online-trained neural network controller for brushless DC motor drives [J].IEEE Trans. On Industry Applications, 2000, 36(2):475-483.

[5] Song Hailong, Yu Yong, Yang Ming et al. A hybrid adaptive fuzzy variable structure speed controller for brushless DC motor[C]. IECON 02: Industrial Electronics Society, Sevilla, Spain, 2002.

[6] Choi J, Park C,Rhyu S, et al. Development and control of BLDCMotor using fuzzy models[C].IEEE Conference on Robotics, Automation and Mechatronics,Singapore,2004.

[7] Almutairi N B., Chow M Y. A modified PI control action with a robust adaptive fuzzy controller applied to DC motor[C]. IJCNN ’01: Neural Networks, Washington, USA, 2001. 
[8] Wai R J. Total sliding-mode controller for PM synchronous motor [J]. Proceedings of the CSEE, 2003, 23(5); 122-127(in Chinese).

[9] LIU H B, WANG J, WU Y H. Study and Simulation of Fuzzy Adaptive PID Control of Brushless DC Motor[J]. Control Engineering of China, 2014, 21(4): 583-587.

[10] GAO W B. Theory and design method of variable structure control [M]. Beijing: Science Press, 1996.

[11] HU Y M. Theory and application of variable structure control [M]. Beijing: Science Press, 2003.

[12] A. Levant. Universal Single-Input-Single-out-put Sliding Mode controller with finite-time converge [J]. IEEE Trans. On Automatic control, 2001, 46(9):1447-1450.

[13] JIA H P, SUN D, HE Y K. Variable structure sliding mode control for PMSM DTC [J]. Proceedings of the CSEE, 2006, 24(20): 134-137.

[14] HUANG Q, ZHOU H Y, LING R. Application of second order sliding mode to brushless DC motor speed control. [J]. Computer Engineering and Applications, 2011, 47(6): 243-245.

[15] TONG K W, ZHANG X, ZHANG X, et al. Sliding Mode Variable Structure Control of PMSM Based on a Nover Reaching Law[J]. Proceeding of the CSEE, 2008, 28(21): 102-106.

[16] LIU Y, ZHOU B, FANG S C. Sliding Mode Control of PMSM Based on a Novel Disturbance Observer [J]. Proceedings of the CSEE, 2010, 30(9): 80-84. 